\title{
Synthesis and Sulphonylation of 4-Amino-3-Methoxymethyl-5- (4-Chlorophenyl)-1H-Pyrazole
}

\author{
Diana I. Persidskaya, Ilya G. Povarov*, \\ Viktor V. Efimov, Alexey V. Lyubyashkin, \\ Georgy A. Suboch and Mikhail S. Tovbis \\ Siberian State University of Science and Technology \\ 31 Krasnoyarsky Rabochy, Krasnoyarsk, 660037, Russia
}

Received 16.03.2018, received in revised form 22.05.2018, accepted 12.08.2018

The paper presents experimental data on the preparation of 1-(4-chlorophenyl)-4-methoxy-1,2,3butanetrione-2-oxime. Its cyclization with the formation of a new substituted nitrosopyrazole was carried out. In the first, 4-amino-3-methoxymethyl-5-(4-chlorophenyl)-1H-pyrazole was obtained and its sulfonylation with p-toluenesulfonyl chloride was carried out. The structure of all compounds is proved by means of IR, UV, NMR spectroscopy. It was found that 4-amino-3-methoxymethyl-5-(4chlorophenyl)-1H-pyrazole in chloroform solution exists as a double ion.

Keywords: Claisen condensation, hydrazine hydrate, nitrosopyrazole, nitrosation, aminopyrazole, sulfonylamide, sulfonylation, IR, UV, NMR spectroscopy.

Citation: Persidskaya D.I., Povarov I.G., Efimov V.V., Lyubyashkin A.V., Suboch G.A., Tovbis M.S. Synthesis and sulphonylation of 4-amino-3-methoxymethyl-5-(4-chlorophenyl)-1h-pyrazole, J. Sib. Fed. Univ. Chem., 2018, 11(3), 369376. DOI: $10.17516 / 1998-2836-0083$.

(c) Siberian Federal University. All rights reserved

* Corresponding author E-mail address: povarov_i@mail.ru 


\title{
Синтез 4-амино-3-метоксиметил-5-(4-хлорфенил)- 1Н-пиразола и его сульфонилирование
}

\author{
Д.И. Персидская, И.Г. Поваров, В.В. Ефимов, \\ А.В. Любяшкин, Г.А. Субоч, М.С. Товбис \\ Сибирский государственный университет науки \\ и технологий имени академика М.Ф. Решетнева \\ Россия, 660037, Красноярск, пр. имени газетьь \\ «Красноярский рабочий», 31
}

В статье приведены экспериментальные данные получения 4-метокси-1-(4-хлорфенил)-1,2,3бутантрион-2-оксима. Осуществлена его ичиклзация с образованием нового замещенного нитрозопиразола. Впервые получен 4-амино-3-метоксиметил-5-(4-хлорфенил)-1Hпиразол и осуществлено его сульфонилирование п-толуолсульфохлоридом. Строение всех соединений доказано с помощью ИК, УФ и ЯМР спектроскопии. Обнаружено, что 4-амино3-метоксиметил-5-(4-хлорфенил)-1Н-пиразол в растворе хлороформа существует в виде двойного иона.

Ключевые слова: конденсация Кляйзена, гидразингидрат, нитрозопиразол, нитрозирование, аминопиразол, сульфониламид, сульфонилирование, ЯМР, ИК, УФ спектроскопия.

\section{Введение}

В настоящее время широкое применение получили различные производные пиразолов. Они входят в состав современных лекарственных препаратов, обладающих жаропонижающими, болеутоляющими, противовоспалительными, а также антибактериальными и фунгицидными свойствами. Среди соединений этого ряда выделяются 4-аминопиразолы, производные которых отличаются высокой биологической активностью [1].

На кафедре органической химии и технологии органических веществ СибГУ непрерывно ведется синтез и изучение свойств ранее неизвестных соединений, обладающих полезными свойствами. Ранее был синтезирован ряд аминопиразолов с арильными, алкоксильными [2] и алкильными заместителями [3] и доказана их фармакологическая активность [4].

Зачастую амины применяются в медицине не в свободном виде, а в виде сульфонилированных производных. Так, очень широко распространены сульфаниламидные препараты группа полученных синтетическим путем соединений, используемых для лечения инфекционных болезней, главным образом, бактериального происхождения [5].

Поэтому целью нашей работы стало получение нового производного 4-аминопиразола и его сульфонильного производного. Для этого нами был синтезирован 4-нитрозо-1Н-пиразол с метоксиметильным и $n$-хлорфенильным заместителями в положениях 3 и 5 соответственно. После его восстановления и обработки $n$-толуолсульфохлоридом было впервые выделено тозильное производное аминопиразола, обладающее потенциальной биологической активностью, и доказано его строение. 


\section{Экспериментальная часть}

4-метокси-1-(4-хлорфенил)-1,3-диоксо-2-бутанид натрия. $29.5 \quad$ г $(0.19$ моль) $n$-хлорацетофенона растворяли в абсолютном диэтиловом эфире. После полного растворения добавляли 9.94 г (0.1 моль) метилметоксиацетата. В полученную реакционную массу порциями вводили 2.5 г (0.11 моль) металлического натрия, при этом через некоторое время наблюдалось активное выделение газа. Смесь кипятили в течение часа на водяной бане с обратным холодильником. Отфильтровывали полученный белый осадок. В результате реакции образовывалась натриевая соль 4-метокси-1-(4-хлорфенил)-1,3-бутандиона. Выход 16 \%, Т пл. 122-123 $\mathrm{C}$. ТСХ в элюенте толуол-этилацетат (1:3) показала индивидуальность продукта. ИК-спектр, $v$, $\mathrm{cm}^{-1}: 1625\left(\mathrm{CH}_{2} \mathrm{C}=\mathrm{O}\right), 1106(\mathrm{COC}), 844(\mathrm{C}-\mathrm{Cl})$.

4-метокси-1-(4-хлорфенил)-1,2,3-бутантрион-2-оксим. Растворяли 3 г (13.2 ммоль) 4-метокси-1-(4-хлорфенил)-1,3-диоксо-2-бутанида натрия в уксусной кислоте (50 мл) и охлаждали до $13{ }^{\circ} \mathrm{C}$. При непрерывном перемешивании порциями добавляли 1.01 г (14.6 ммоль) нитрита натрия в течение часа так, чтобы температура была в интервале от 13 до $15{ }^{\circ} \mathrm{C}$, и отслеживали протекание реакции методом тонкослойной хроматографии. Смесь разбавляли водой и отфильтровывали белые кристаллы. Выход продукта 68 \%, Т пл. 135-136 ${ }^{\circ} \mathrm{C}$, ТСХ в элюенте толуол-этилацетат (1:3) показала индивидуальность продукта. ИК-спектр, $v, \mathrm{~cm}^{-1}$ : $1671\left(\mathrm{CH}_{2} \mathrm{C}=\mathrm{O}\right), 1111$ (COC), 836,51 (C-Cl). В спектре ЯМР ${ }^{13} \mathrm{C}$ присутствовали сигналы всех атомов углерода.

3-метоксиметил-4-нитрозо-5-(4-хлорфенил)-1Н-пиразола Навеску 0.4 г (1.6 ммоль) изонитрозодикетона растворяли в минимальном объеме этанола (10 мл). Добавляли 0,086 г (1.7 ммоль) гидразингидрата и ставили перемешивать. Контроль реакции проводили с помощью метода ТСХ. Спустя 2 ч выпадал осадок зеленого цвета. После фильтрования были выделены зеленые кристаллы 3-метоксиметил-4-нитрозо-5-(4-хлорфенил)-1Н-пиразола. Выход составил 61 \% Т пл. $145-146{ }^{\circ} \mathrm{C}$. ТСХ в элюенте толуол-этилацетат (1:3) показала индивидуальность продукта. ИК-спектр, $v, \mathrm{~cm}^{-1}: 844$ (C-Cl), 1106 (СОC), 1396 (NO). В спектре ЯМР ${ }^{13} \mathrm{C}$ присутствовали сигналы всех атомов углерода.

4-амино-3-метоксиметил-5-(4-хлорфенил)-1Н-пиразол. В 10 мл воды растворяли 0,5 г 3-метоксиметил-4-нитрозо-5-(4-хлорфенил)-1Н-пиразола при температуре $60{ }^{\circ} \mathrm{C}$. Добавляли порционно 1,5 г дитионита натрия и перемешивали в течение 8 ч при $60{ }^{\circ} \mathrm{C}$. Затем раствор охлаждали до комнатной температуры. Осадок отфильтровывали и сушили под вакуумом. ТСХ в элюенте толуол-этилацетат (3:1) показала индивидуальность продуктов. Выход продукта $23 \%$. Кристаллы белого цвета, Т пл. $=106{ }^{\circ} \mathrm{C}$. ИК-спектр, v, $\mathrm{cm}^{-1}: 3375$ (NH2), 3150 (NH), 1083 (СОС), 832 (C-Cl). Масс спектр: m/z (Іотн, \%): 239(32,63), 237(100), 207(21,72), 206(27,93), 205(29,23), 170(43,04), 138(22,42).

$N$-(5-(4-хлорфенил)-3-(метоксиметил)-1H-пиразол-4-ил)-4-метилбензолсульфамид. Для осуществления сульфонилирования в колбу загружали 0,1 г 4-амино-3-метоксиметил5-(4-хлорфенил)-1Н-пиразола и 4 мл воды. Реакцию проводили при непрерывном перемешивании и нагревании до $60{ }^{\circ} \mathrm{C}$. В течение 1 ч небольшими порциями прибавляли по 0,1 г $n$-толуолсульфохлорида и по 0,03 г соды, следя за тем, чтобы реакция среды была нейтральной. Затем смесь перемешивали в течение 2 ч, охлаждали до комнатной температуры. Для очистки от исходного аминопиразола в реакционную массу по каплям добавляли концентрированную 
соляную кислоту, доводя раствор до кислой реакции по Конго, после чего перемешивали еще 30 мин при комнатной температуре. Полученный осадок отфильтровывали и промывали водой от кислоты до нейтральной реакции, затем сушили под вакуумом. Тонкослойная хроматограмма в элюенте толуол-этилацетат (1:1) показала индивидуальность продуктов. Выход составил 60 \%, Т пл. 171-172 ${ }^{\circ} \mathrm{C}$. ТСХ в элюенте толуол-этилацетат (1:3) показала индивидуальность продукта. В ИК-спектре наблюдается полоса валентного колебания $\mathrm{SO}_{2}$-группы в области $1094 \mathrm{~cm}^{-1}$.

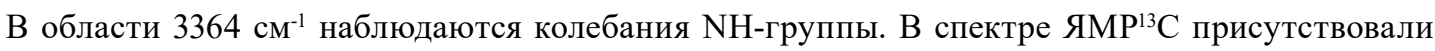
сигналы всех атомов углерода.

\section{Результаты и их обсуждение}

Синтез N-(5-(4-хлорфенил)-3-(метоксиметил)-1Н-пиразол-4-ил)-4-метилбензолсульфамида был осуществлен по схеме, приведенной на рис. 1. Соединения 1-5 были получены впервые, их строение доказано методами ИК, УФ, ЯМР ${ }^{1} \mathrm{H}$ и ${ }^{13} \mathrm{C}$ спектроскопии, масс-спектрометрии. Отнесение сигналов ЯМР ${ }^{13} \mathrm{C}$ к конкретным атомам углерода проводили с использованием ${ }^{1} \mathrm{H}-{ }^{13} \mathrm{C}$ HSQC корреляционной спектроскопии.

Методом сложноэфирной конденсации Кляйзена [6] между $n$-хлорацетофеноном и метилметоксиацетатом в абсолютном диэтиловом эфире над металлическим натрием была получена натриевая соль 1-(4-хлорфенил)-4-метоксибутандиона-1,3 (1).

При нитрозировании натриевой соли дикетона (1) нитритом натрия в ледяной уксусной кислоте был получен 4-метокси-1-(4-хлорфенил)-1,2,3-бутантрион-2-оксим (2). Введение изонитрозодикетона (2) в реакцию конденсации с гидразингидратом в этиловом спирте позволило синтезировать 3-метоксиметил-4-нитрозо-5-(4-хлорфенил)-1Н-пиразол (3). Восстановление ни-<smiles>COCC(=O)OCC(=O)c1ccc(Cl)cc1</smiles><smiles>COCc1n[nH]c(-c2ccc(Cl)cc2)c1[N+](=O)[O-]</smiles><smiles>COCc1n[nH]c(-c2ccc(Cl)cc2)c1N</smiles>

Рис. 1. Синтез N-(5-(4-хлорфенил)-3-(метоксиметил)-1Н-пиразол-4-ил)-4-метилбензолсульфамида

Fig. 1. Synthesis of N-(5-(4-chlorophenyl)-3-(methoxymethyl)-1H-pyrazole-4-yl)-4-methylbenzenesulfamide 
трозопиразола (3) проводили двумя параллельными методами: дитионитом натрия в воде (метод А) и гидразингидратом на палладиевом катализаторе в дихлорметане (метод Б). Получение аминопиразола (4) по методу Б оказалось более эффективным с точки зрения практического выхода, чистоты продукта и времени реакции. По реакции сульфонилирования аминопиразола (4) в водной среде был получен целевой N-(5-(4-хлорфенил)-3-(метоксиметил)-1Н-пиразол4-ил)-4-метилбензолсульфамид (5).

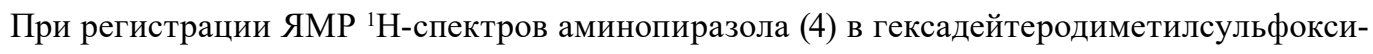
де (рис. 2) и в дейтерохлороформе (рис. 3) выяснилось, что спектры данного соединения существенно различаются.

Так, в ДМСО наблюдается сигнал двух протонов аминогруппы и сигнал очень кислого протона NH группы кольца в области 12.49 м.д. При этом сигналы всех групп «двоятся». Это

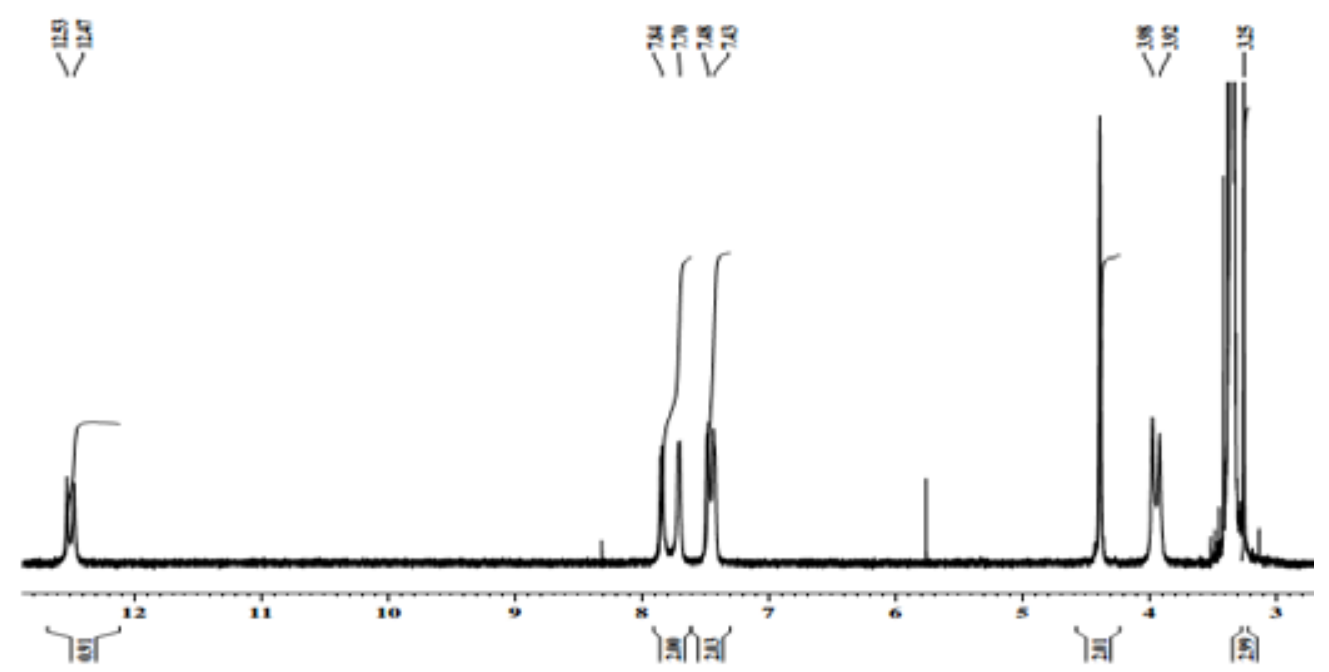

Рис. 2. ЯМР ${ }^{1} \mathrm{H}$ спектр 3-метоксиметил-4-амино-5-(4-хлорфенил)-1Н-пиразола в ДМСО- $\mathrm{d}_{6}$

Fig. 2. NMR ${ }^{1} \mathrm{H}$ spectrum of 3-methoxymethy-4-amino-5-(4-chlorophenyl)-1H-pyrazole in DMSO- $\mathrm{d}_{6}$

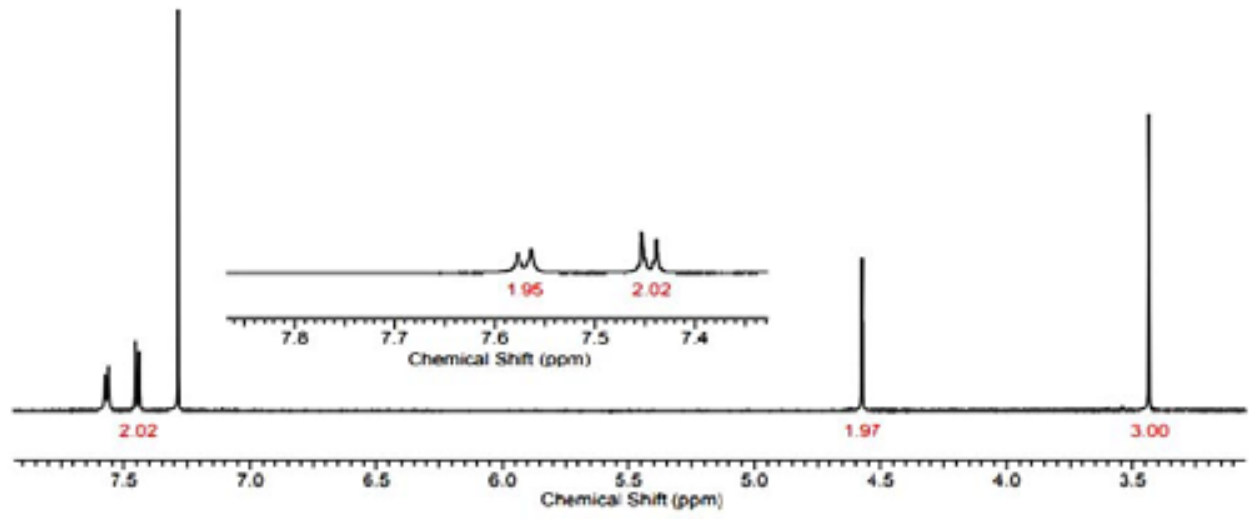

Рис. 3. ЯМР ${ }^{1} \mathrm{H}$ спектр 3-метоксиметил-4-амино-5-(п-хлорфенил)-1Н-пиразола в $\mathrm{CDCl}_{3}$

Fig. 3. NMR ${ }^{1} \mathrm{H}$ spectrum of 3-methoxymethy-4-amino-5-(p-chlorophenyl)-1H-pyrazole in $\mathrm{CDCl}_{3}$ 
может объясняться таутомерным равновесием с переходом протона от одного атома азота пиразольного кольца к другому.<smiles>COCc1n[nH]c(-c2ccc(Cl)cc2)c1N</smiles><smiles>CC=Cc1[nH]nc(-c2ccc(Cl)cc2)c1N</smiles>

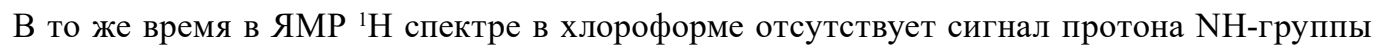
пиразольного кольца в слабом поле, а число протонов в аминогруппе по интегральной сумме увеличивается до трех, и ее сигнал сдвигается в область более слабого поля.

Это явление может объясняться тем, что протон NH-группы пиразольного кольца мог перейти к аминогруппе.<smiles>COCc1n[nH]c(-c2ccc(Cl)cc2)c1N</smiles><smiles>COCc1n[nH]c(-c2ccc(Cl)cc2)c1[NH3+]</smiles>

Образующийся своеобразный цвиттер-ион в полярном растворителе $\left(\mathrm{CDCl}_{3}\right)$ хорошо сольватируется, в то время как в ДМСО сольватация аниона не может осуществляться [7], по этой причине такой двойной ион в диметилсульфоксиде не образуется.

Отнесение сигналов ЯМР ${ }^{1} \mathrm{H}$ и ЯМР ${ }^{13} \mathrm{C}\left(\mathrm{CDCl}_{3}\right)$ сульфонилированного аминопиразола (5) к конкретным атомам углерода проводили с использованием ${ }^{1} \mathrm{H}-{ }^{13} \mathrm{C}$ HSQC, ${ }^{1} \mathrm{H}-{ }^{1} \mathrm{H}$ COSY и ${ }^{1} \mathrm{H}-{ }^{13} \mathrm{C}$ НМВС корреляционной спектроскопии.

Так, в ЯМР ${ }^{1} \mathrm{H}$ спектре (рис. 4) сигнал протонов метильной группы тозильного заместителя регистрируется с хим. сдвигом 2,36 м.д. Сигналы метильной и метиленовой групп метоксиметильного заместителя зарегистрированы в виде синглетов с хим. сдвигом 3,44 и 4,45 м.д. соответственно. В области 6,29 м.д. присутствует сигнал протона сульфамидной группы. Протоны 2-го атома углерода 4-хлорфенильного заместителя имеют хим. сдвиг 7,18 м.д., а 4-го атома углерода - 7,23 м.д. Протоны тозильного заместителя зарегистрированы с хим. сдвигами 7,03 м.д. (орто) и 7,4 м.д. (мета).

Так, в ЯМР ${ }^{13} \mathrm{C}$ спектре (рис. 5) сигналы атомов углерода метоксиметильной группы имеют хим. сдвиги 58,82 и 64,98. Сигналы тозильного заместителя: 127,12, 129,18, 135,42, 143,96, Сигналы $n$-хлорфенильного заместителя: $128,17,128,40,134,42,144,55$. Три сигнала пиразольного кольца: $112,07,135,47,143,34$.

\section{Заключение}

1. Разработаны общие принципы синтеза нового $n$-толуолсульфонильного (тозильного) производного 4-аминопиразола.

2. В результате работы синтезированы новые соединения ряда пиразола и его сульфонильное производное. 


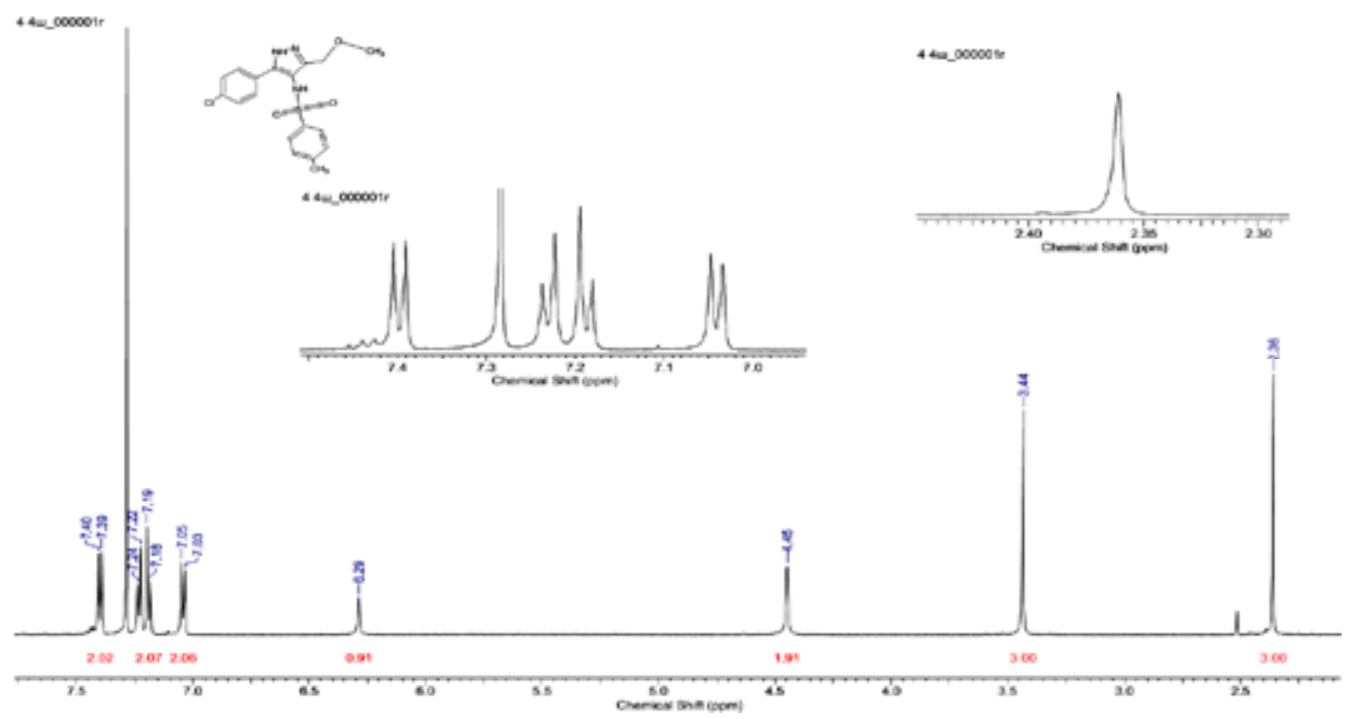

Рис. 4. ЯМР ${ }^{1} \mathrm{H}$ спектр N-(5-(4-хлорфенил)-3-(метоксиметил)-1Н-пиразол-4-ил)-4-метилбензолсульфамида в $\mathrm{CDCl}_{3}$

Fig. 4. NMR ${ }^{1} \mathrm{H}$ spectrum of N-(5-(4-chlorophenyl)-3-(methoxymethyl)-1H-pyrazole-4-yl)-4methylbenzenesulphamide in $\mathrm{CDCl}_{3}$

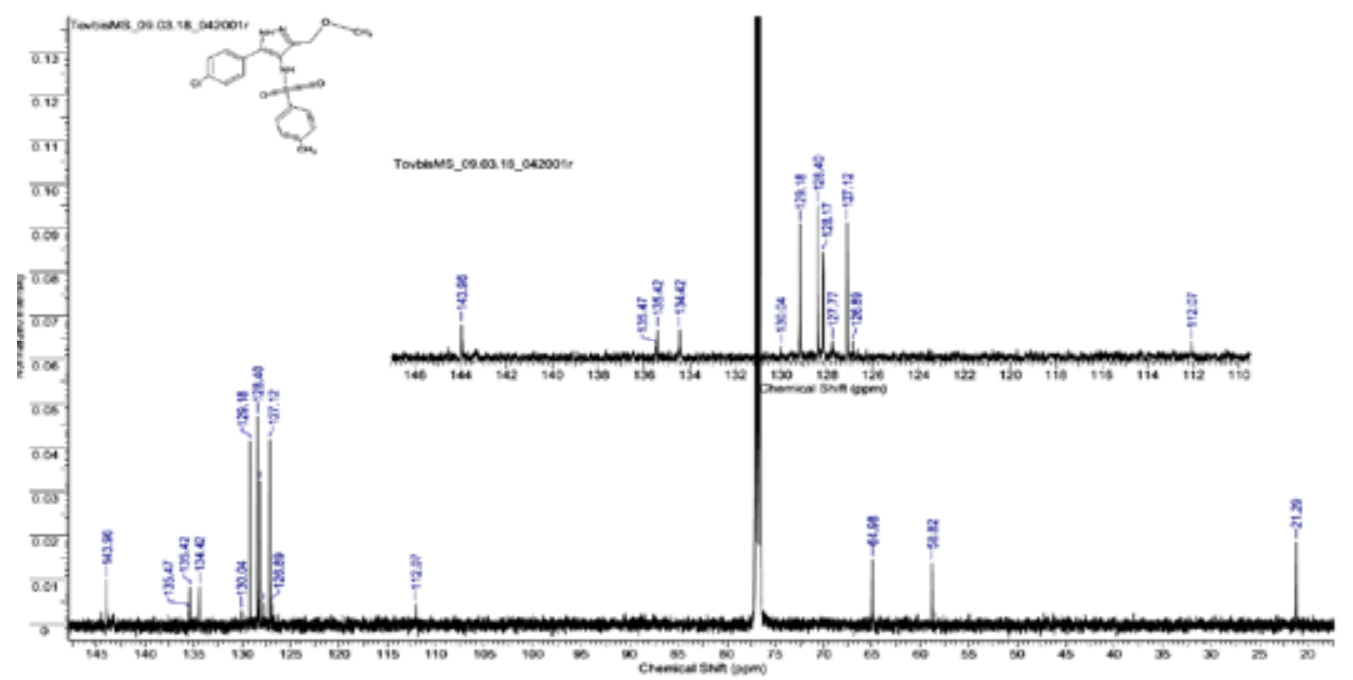

Рис. 5. ЯМР ${ }^{13} \mathrm{C}$ спектр N-(5-(4-хлорфенил)-3-(метоксиметил)-1Н-пиразол-4-ил)-4-метилбензолсульфамида в $\mathrm{CDCl}_{3}$

Fig. 5. NMR ${ }^{13} \mathrm{C}$ spectrum of $\mathrm{N}-(5-(4-c h l o r o p h e n y l)-3-(m e t h o x y m e t h y l)-1 H-p y r a z o l e-4-y l)-4-$ methylbenzenesulphamide in $\mathrm{CDCl}_{3}$

3. Структура всех впервые синтезированных соединений доказана с помощью современных методов спектрального анализа: ИК, УФ ЯМР ${ }^{1} \mathrm{H},{ }^{13} \mathrm{C}$ и корреляционной спектроскопии, масс-спектрометрии.

4. Впервые показано, что 4-амино-3-метоксиметил-5-(4-хлорфенил)-1Н-пиразол в растворе хлороформа может существовать в виде двойного иона. 


\section{Список литературы}

1. ДаниловЕ.А.,ИсляйкинМ.К.Введениевхимиюитехнологиюхимико-фармачевтических препаратов. Под ред. Г.П. Шапошникова. Иваново: Иван. гос. хим.-технол. ун-т, 2002. 284 с. [Danilov E.A., Islyaikin M.K. Introduction to Chemistry and Technology of Chemical-Pharmaceutical Preparations. Under Ed. Shaposhnikova G.P. Ivanovo: Ivan. State chem.-tech. university, 2002. 284 p. (In Russ.)].

2. Любяшкин А.В., Ефимов В.В, Субоч Г.А. и др. Синтез новых алкоксиметилзамещенных 4-амино-1Н-пиразолов и их ацилирование. Журнал органической химии 2016. Т. 56, С. 52-54. [Lyubiashkin A.V., Efimov V.V., Suboch G.A. and others. Synthesis of new alkoxymethyl-substituted 4-amino-1H-pyrazoles and their acylation. Journal of Organic Chemistry 2016. Vol. 56, P. 52-54. (In Russ.)]

3. Любяшкин А.В., Ефимов В.В., Бобров П.С., Петерсон И.В.,. Товбис М.С, Субоч Г.А. Получение 4-амино-3-метил-5-(2-нафтил)-1Н-пиразола и его ацильных производных. Вестник технологического университета. Казань. 2016. T 19(15), C. 15-16. [Lyubyashkin A.V., Efimov V.V., Bobrov P.S., Peterson I.V., Tovbis M.S., Suboch G.A. Preparation of 4-amino-3-methyl-5-(2naphthyl) -1H-pyrazole and its acyl derivatives. Bulletin of the Technological University. Kazan. 2016. Vol. 19(15), P. 15-16. (In Russ.)]

4. Машковский М.Д. Лекарственные средства. В 2 т. 14-е изд., перераб. и доп. М.: Медицина, 2000. T. 1, 736 с.; Т. 2, 688 с. [Mashkovsky M.D. Medicinal products. In 2 parts. 14 th ed., rev. M.: Medicine, 2000. Vol. 1, 736 p., Vol. 2, 688 p. (In Russ.)]

5. Sharshira E.M., Hamada, N.M.M. Synthesis and Antimicrobial Evaluation of Some Pyrazole Derivatives. Molecules 2012. Vol. 17, P. 4962-4971.

6. Zawadiak J. UV absorption and keto-enol tautomerism equilibrium of methoxy and dimethoxy 1,3-diphenylpropane-1,3-diones. Spectrochimica Acta 2010. Vol. 75, P. 925-929.

7. Персидская Д.И., Ефимов В. В., Товбис М. С. Синтез ранее неизвестного 1-(пхлорфенил)-4-метокси-1,2,3-бутантриона-2-оксима и нитрозопиразола на его основе. Сборник материалов Всероссийской научно-практической конференции «Лесной и химический комплексы - проблемы и решения» 2017. T. 1, C. 467-469. [Persidskaya D.I., Efimov V.V., Tovbis M.S. Synthesis of the previously unknown 1-(p-chlorophenyl)-4-methoxy-1,2,3-butanetrione-2-oxime and nitrosopyrazole based on it materials of the All-Russian scientific-practical conference "Forest and chemical complexes - problems and solutions” 2017. Vol. 1, P. 467-469 (In Russ.)] 